\title{
The Innovative Teaching Mode Research of Database Principle Based on Information Technology Environment
}

\author{
Lingxing Yang ${ }^{1,}$ a , Zhongyu Zhang ${ }^{2, b}$ \\ ${ }^{1}$ Physics and Electronic Engineering College, Qujing Normal University, Qujing, 655011, China \\ ${ }^{2}$ Physics and Electronic Engineering College, Qujing Normal University, Qujing, 655011, China \\ aemail:84759653@qq.coom, bemail:49658669@qq.com
}

\section{Keywords: Information Environment; Role-exchanging; Task-driving; Automatic learning}

\begin{abstract}
Database principle is quite an important elementary course in education technology, and the question how to guide students to effectively learn it has been puzzling teachers all the time. In response to this phenomenon, this paper describes that with the support of the IT environment, teachers break the traditional teaching methods and students change the old learning modes. With their role exchanging, the teaching and learning efficiency can be highly improved. We present an idea that, students are dominating and teachers are coaching. With teachers' guiding, inspiration and task-driving, students would use the innovative teaching modes combined with autonomic learning and collaborative learning to achieve great teamwork spirit and explore ability.
\end{abstract}

\section{Introduction}

Information technology advances with each passing day. In recent years, new things like cloud technology, microblog, Vsins, intelligent devices and mobile office applications are emerging in endlessly, so it is easy for us to realize that information technology is working in all aspects of the society. And obviously, it has influence on the teaching and learning of college courses. How to use information resources to improve the teaching quality and learning effect is a subject worthy of study. Author adopts the innovative teaching mode on the Educational Technology major students in the Qujing Normal University. Observation shows that the effect is much better than the traditional one. Students' manipulative ability and teamwork spirit are highly improved. More importantly, they are able to do independent thinking when facing new problems. They consult relevant literatures and work cooperatively with other students, which, in our opinion, are the key for applied talents.

\section{Traditional teaching methods and the existing problems}

Database is a significant elementary course in college professions, and many universities regard it as a required course. The basic knowledge of database is playing a pivotal role in the information society, teachers, students and people engaged in the information technology construction shall master it. However, according to author's survey on the database course implementation in Qujing Normal University as well as related domestic teaching materials, he found that there are common problems in the database teaching process.

(1) Teaching content is not keeping pace with the times

The author has been teaching database course for more than ten years. He analyzes domestic universities and discovers that the teaching materials on the field are relatively inflexible. Materials would be updated every five years or so, but the update rate is quite slow, so they are not matching the database technology development. Most of the teachers are teaching according to the textbook step by step, and are not keeping abreast of new developments in database technology. Students trained like this cannot meet the needs of the developing information society.

(2) Evaluation mode is holding their potential back 
All the while, database course evaluates students using written examinations. But it was found that, some students get good results with no real grasp of database knowledge, but some students fail their exams although they are very familiar with the basic principles and apply them to the actual projects. So, seeing this phenomenon from any aspect, we think it is extremely unreasonable. Thus, we need to reform the assessment methods. We shall individualize assessment according to specific conditions, and try to test their comprehensive knowledge. In this way, we can objectively get the full and real assessments.

(3)The teaching methods seriously hinders students' learning motivation

Usually, teachers use the same teaching methods as other theoretical courses. Generally they organize teaching like: concept $\rightarrow$ example $\rightarrow$ practice, thus, students accept and master the basic course knowledge [1] passively. So that students cannot fully understand what they learn. When it comes to tests, they totally rely on memory or speculative ways. When it comes to actual database design, they would be completely at a loss. The vast majority of teachers teach using lectures. Standing on the platform, they explain and instruct knowledge to students bit by bit. Students would only passively follow the teachers' instruction and take notes, read their favorite books or some students even do not listen in class. In this condition, classroom discipline is out of order, teachers and students do things in their own way, teaching effect is terrible, and students don't have room for active learning.

\section{(4) Theory and practical link is disjointed}

The purpose of database technology development is for better application. Database technology is a very practical course, and it is closely related to the information systems of all walks of life in the modern society. Database basis construction and application level have become important indicators of national informatization level. Current teaching tends to focus on the theory study while ignoring the practical links. Without practice, students cannot fully understand and strengthen the knowledge they learned. If teachers don't guide them to do practice and develop actual projects, it would be very difficult for students to reach practical abilities. Social requirements on databases talents are increasingly high. In this situation, only solid theoretical knowledge learning and practice can help them remain invincible in work.

\section{Innovative teaching modes under the IT environment}

Because of the drawbacks of database teaching, the trained students are inadaptable to the social needs. In addition to learning method innovation, teaching mode exploration is also necessary. With the support of mature IT, advanced tools and instruments, integrated teaching resources, we shall break the traditional teaching thinking, and give students opportunities to explore and solve new problems. In this way, not only the teaching effectiveness can be improved, but also the knowledge and emotional exchanges between students and teachers are deepened. Students would be interested in participating in the teaching and research work. And at the same time, they foster science literacy, collaborative problem-solving skills and innovative team spirit. Under the IT environment, teaching mode innovation has its realistic basis for implementation. With the key of shift in thinking, it is simple to operate. The main points are listed below.

\section{(1) Integrate existing teaching resource and excavate potential learning resource}

Educational resources are the foundation of learning, and also prerequisite for teaching. Traditional educational resources are mostly papers which are inconvenient for learning and sharing. With developed information technology, learning and teaching resource are rich, and we have multimedia courseware, electronic handouts, and various types of electronic examination forms. Using the existing electronic educational resources, and through the network course and high-quality curriculum construction, we centralize and deploy all the related resources. Thus, it will be easy and convenient for students to access and browse endless materials. Pay attention to the latest trends of database technology, and update new technology and new applications into 
educational resources, so students will know the development trend and the application. Search for the demonstration lesson and quality course website of similar curriculum in major universities at home and abroad, so students can learn these high-quality education resources through internet anytime and anywhere, so as to share worldwide educational resources.

(2) Implement the teaching idea of "students are dominating and teachers are coaching"

Under the IT environment, teaching mode changes. Teachers are no longer simple knowledge initiator, but course designer, teaching environment creator, student learning supervisor, learning process instructor, learning effect valuator and learning potential detective [2]. Teachers shall give up the traditional indoctrination teaching model, coach and inspire them in learning. The new teaching model shall be student-centered. Ideally, teachers raise questions in advance, so that students do group discussion and idea exchange, learn from each other, and work out innovative solutions together. Then, teachers review, let students summarize their achievements and shortcomings, and understand their future learning direction. During this process, teachers guide students and stimulate students 'desire for knowledge, but ensure that they are not daunted. Timely, they solve the problems in the students' learning process and guide and plan for students in their uncharted territory.

\section{(3) Task-driving and inquiry learning}

WebQuest model is proved to have commendable learning effect. Taking database curriculum as an example, teachers make assignments at the beginning of the course. Task categories can be diverse and including all difficulty levels so students with different abilities can choose suitable ones for themselves. However, the essential requirement is not to copy, but can only acquire through inquiry learning, otherwise the results would be invalid. Let the students learn WebQuest mode on their own, and carry it out according to the operation instruction. WebQuest has five basic principles: F-find wonderful website; O-organize your learners and learning resources effectively; C-students consider; U-use media; S-provide scaffolding[3]for high learning expectations. Adopting WebQuest model for inquiry learning is not to let give them up but to provide more demands. Students have clear motivation, use cognitive psychology and constructivism ideas, and also adopt collaborative learning. However, teachers shall observe the problems of their performance in the complex process, and correct their mistakes promptly. Task-driving and inquiry learning are not new ideas, the key is to design rational tasks and ensure full implementation.

\section{(4) Select appropriate content for students' autonomous learning and independent practice}

Existing conditions are mature, and local resources and network resources are rich. Furthermore, there are specialized database network courses and learning websites for share. Teachers neatly select appropriate content for students' autonomous study and evaluate the effect. That includes course content learning, practice content learning. Students can raise and solve their own questions, and teachers grasp the progress and provide help. Autonomous learning can run through the whole curriculum, but it cannot replace teaching, or play the dominant role. It has flexible and diverse ways for implementation, such as online learning or book learning, and they do it in spare time or in class. But teachers should have evaluation criteria and evaluation system. When student do online learning using of network courses, teachers shall communicate, answer students' questions, supervise and help students to complete the learning task. Also, students can prepare in advance, explain the contents of their own learning in the class, teacher sum up after the students discussed about it. In this way, we can have a clear learning test, and a practice of students' presentation skill. In the autonomous learning model, students changed from the passive role into the active role. With the teachers' guidance, they identify learning objectives, grasp the learning progress and complete exercises until the final completion of the assessment. Most importantly, they have a chance to form active learning attitude and habit [4]. Autonomous learning gives students enormous free space, so they can develop learning program according to their actual condition. They can work with each other, discuss and help each to solve the problems through the combination of theory and practice. 
Furthermore, they can learn new knowledge together with teachers. Under this circumstance, both students’ learning ability and the teaching quality can be highly enhanced.

\section{Conclusion}

Improving the teaching quality and learning effect is a complicated project which cannot be done overnight, or by simple teaching reform or learning method developing. This paper starts from the existing problems of the traditional teaching methods, and analyzes the adverse impact of these problems. And then discusses how to take advantage of mature technologies and tools to build a foundation for innovative teaching and inquiry learning, and analyze the teaching effectiveness of innovative models. Admittedly, these teaching innovative methods cannot be used mechanically, and is not suitable for every single student. So we should operate it according to the actual situation of the students, a have a definite purpose. But these ideas have much in common, and have some merits in conducting practical teaching. So we believe it can provide reference for other courses teaching innovation.

\section{References}

[1] Bai Yang. Research on course teaching model[J] Based on case-driven " Principle and Application of Database” . Computer Knowledge and Technology,2012,18(1):5-6.

[2] Xie Qing. Course Teaching Mode Practice and Analysis on Database Technology and Application under the Network Environment [J]. Journal of computer education,2009(12).

[3] The universal teaching mode and teaching strategies in the IT environment [EB/OL]. http://ybpengzhi.blog.163.com/blog/static/133369302201091053754593,2010-10-10/2013-03-17.

[4]Silin Zhou, etc. Teaching model research on Database Application Technology based on autonomous learning [J]. Journal of software Guide,2013,12(1):198-199. 